\title{
Front Matter: Volume 8197
}

, "Front Matter: Volume 8197," Proc. SPIE 8197, 2011 International Conference on Optical Instruments and Technology: Optical Systems and Modern Optoelectronic Instruments, 819701 (4 January 2012); doi: $10.1117 / 12.922950$

SDIE Event: International Conference on Optical Instruments and Technology (OIT2011), 2011, Beijing, Beijing, China 


\title{
PROCEEDINGS OF SPIE
}

\section{International Conference on Optical Instruments and Technology \\ Optical Systems and Modern Optoelectronic Instruments}

\author{
Yongtian Wang \\ Yunlong Sheng \\ Han-Ping Shieh \\ Kimio Tatsuno \\ Editors
}

6-9 November 2011

Beijing, China

Sponsored by

$\mathrm{CIS}$ - China Instrument and Control Society

COS - The Chinese Optical Society

SPIE

\section{Cooperating Organizations}

Opto-Electronic - Mechanic Technology and System Integration Chapter, CIS (China) • Beijing Institute of Technology (China) • University of Shanghai for Science and Technology (China) Capital Normal University (China) • Optical Instrument Chapter, CIS (China) • Committee on Optoelectronic Technology, COS (China) • Beijing Hamamatsu Photon Techniques Inc. (China) Tianjin University (China) • Zhejiang University (China) • Tsinghua University (China) • Chongaing University (China) • Nanjing University (China) • Instrument Society of America (China) • Institute of Measurement and Control (United Kingdom) • Hong Kong Institution of Engineers (China) The Society of Measurement and Control (Japan)

Published by

SPIE

Volume 8197 
The papers included in this volume were part of the technical conference cited on the cover and title page. Papers were selected and subject to review by the editors and conference program committee. Some conference presentations may not be available for publication. The papers published in these proceedings reflect the work and thoughts of the authors and are published herein as submitted. The publisher is not responsible for the validity of the information or for any outcomes resulting from reliance thereon.

Please use the following format to cite material from this book:

Author(s), "Title of Paper," in 2011 International Conference on Optical Instruments and Technology: Optical Systems and Modern Optoelectronic Instruments, edited by Yongtian Wang, Yunlong Sheng, Han-Ping Shieh, Kimio Tatsuno, Proceedings of SPIE Vol. 8197 (SPIE, Bellingham, WA, 2011) Article CID Number.

ISSN 0277-786X

ISBN 9780819488381

Published by

SPIE

P.O. Box 10, Bellingham, Washington 98227-0010 USA

Telephone +1 3606763290 (Pacific Time) · Fax +1 3606471445

SPIE.org

Copyright ( 2011, Society of Photo-Optical Instrumentation Engineers

Copying of material in this book for internal or personal use, or for the internal or personal use of specific clients, beyond the fair use provisions granted by the U.S. Copyright Law is authorized by SPIE subject to payment of copying fees. The Transactional Reporting Service base fee for this volume is $\$ 18.00$ per article (or portion thereof), which should be paid directly to the Copyright Clearance Center (CCC), 222 Rosewood Drive, Danvers, MA 01923. Payment may also be made electronically through CCC Online at copyright.com. Other copying for republication, resale, advertising or promotion, or any form of systematic or multiple reproduction of any material in this book is prohibited except with permission in writing from the publisher. The CCC fee code is 0277-786X/11/ \$18.00.

Printed in the United States of America.

Publication of record for individual papers is online in the SPIE Digital Library.

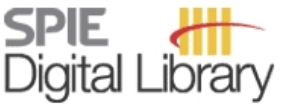

SPIEDigitalLibrary.org

Paper Numbering: Proceedings of SPIE follow an e-First publication model, with papers published first online and then in print and on CD-ROM. Papers are published as they are submitted and meet publication criteria. A unique, consistent, permanent citation identifier (CID) number is assigned to each article at the time of the first publication. Utilization of CIDs allows articles to be fully citable as soon as they are published online, and connects the same identifier to all online, print, and electronic versions of the publication. SPIE uses a six-digit CID article numbering system in which:

- The first four digits correspond to the SPIE volume number.

- The last two digits indicate publication order within the volume using a Base 36 numbering system employing both numerals and letters. These two-number sets start with $00,01,02,03,04$, $05,06,07,08,09,0 A, 0 B \ldots 0 Z$, followed by 10-1Z, 20-2Z, etc.

The CID number appears on each page of the manuscript. The complete citation is used on the first page, and an abbreviated version on subsequent pages. Numbers in the index correspond to the last two digits of the six-digit CID number. 


\title{
Contents
}

\author{
ix Symposium Committee \\ xi Conference Committee \\ xiii Introduction
}

\section{PLENARY SESSION}

819702 Applications of optical measurement technology in pollution gas monitoring at thermal power plants (Plenary Paper) [8197-92]

J. Wang, D. Yu, Focused Photonics (Hangzhou) Inc. (China); H. Ye, Zhejiang Univ. (China);

J. Yang, L. Ke, S. Han, H. Gu, Y. Chen, Focused Photonics (Hangzhou) Inc. (China)

\section{SESSION 1 OPTICAL MEASUREMENT}

819703 Long distance measurement with submicrometer accuracy (Invited Paper) [8197-88]

N. Bhattacharya, M. Cui, M. G. Zeitouny, H. P. Urbach, Technische Univ. Delft (Netherlands);

S. A. van den Berg, VSL (Netherlands)

819704 Stereo vision system based on the laser dot matrix projection [8197-51]

C. Liu, S. Ma, Q. Ma, X. Zeng, Beijing Institute of Technology (China)

819705 An off-axis optical system design applied in the precision measurement of axle hole's inner diameter [8197-78]

H. Xie, F. Li, T. Li, T. Yang, Tianjin Univ. (China)

819706 Flying attitude measurement of projectile using high speed photography and 3D digital image correlation technique [8197-52]

X. Zeng, S. Ma, Beijing Institute of Technology (China)

\section{SESSION 2 OPTICAL SENSING AND TESTING}

819707 Fiber optic multipoint pressure and temperature sensing system using BOF/DWPR (Invited Paper) [8197-89]

S. Onoda, K. Inove, M. Nakano, Y. Komatsu, Watanabe Co., Ltd. (Japan)

819709 The instrument of high-precision photoelectric autocollimator based on PSD [8197-17]

X. Zhang, Z. An, Changchun Univ. of Science and Technology (China)

8197 OA Comparison of wavefront reconstruction with modal method and zonal method for the inspection of catadioptric projection optics using Hartmann wavefront sensor [8197-93] J. Wang, K. Liu, Y. Li, H. Wang, G. Li, Beijing Institute of Technology (China) 
8197 OB Fourier analysis of metallic near-field superlens (Invited Paper) [8197-85]

Y. Sheng, G. Tremblay, Y. Gravel, COPL, Univ. of Laval (Canada)

8197 OC Design of waveguide grating filter with an antireflective surface using approximate and rigorous methods [8197-16]

T. Sang, T. Cai, W. Zhou, X. Zhang, F. Liu, Qiannan Normal College for Nationalities (China)

8197 OD Analysis of microstructure heights error of multilayer diffractive optical elements for far infrared optical system [8197-25]

L. Yang, Q. Cui, C. Xue, T. Liu, Changchun Univ. of Science and Technology (China)

\section{SESSION 4 OPTICAL ELEMENTS AND SYSTEMS}

8197 OF Design and test of a high-contrast imaging coronagraph based on two 50-step transmission filters [8197-82]

J. Dou, Nanjing Institute of Astronomical Optics \& Technology (China) and Key Lab. of Astronomical Optics \& Technology (China); D. Ren, Nanjing Institute of Astronomical Optics \& Technology (China), Key Lab. of Astronomical Optics \& Technology (China), and California State Univ., Northridge (United States); Y. Zhu, Nanjing Institute of Astronomical Optics \& Technology (China) and Key Lab. of Astronomical Optics \& Technology (China); X. Zhang, X. Wang, Nanjing Institute of Astronomical Optics \& Technology (China), Key Lab. of Astronomical Optics \& Technology (China), and Graduate Univ. of the Chinese Academy of Sciences (China)

8197 OG Design of the cooled IRFPA real-time non-uniformity correction system based on FPGA [8197-71]

Y. Sheng, L. Yun, J. Shi, C. Zhang, Yunnan Normal Univ. (China)

$8197 \mathrm{OH} \quad$ Design of OLED gamma correction system based on the LUT [8197-46]

Y. Tai, L. Yun, J. Shi, Z. Chen, Q. Li, Yunnan Normal Univ. (China)

\section{SESSION 5 OPTICAL SYSTEMS DESIGN}

8197 Ol Developments in modern panoramic lenses: lens design, controlled distortion, and characterization (Invited Paper) [8197-81]

S. Thibault, J. Parent, H. Zhang, M. Larivière-Bastien, A.-S. Poulin-Girard, A. Arfaoui, P. Désaulniers, COPL, Univ. Laval (Canada)

8197 0J A universal and smart helmet-mounted display of large FOV (Invited Paper) [8197-76] N. Zhang, D. Weng, Y. Wang, X. Li, Y. Liu, Beijing Institute of Technology (China)

8197 OK The comparison of different medical electronic endoscope systems [8197-31] W. Ye, L. Wang, H. Duan, Zhejiang Univ. (China)

8197 OL Optimization design of suspension biochip detection system [8197-68] G. Xu, Y. Bu, Anhui Univ. of Technology (China) and Zhejiang Univ. (China); L. Wang, Zhejiang Univ. (China) 
8197 OM Testing of a high-contrast imaging coronagraph based on an active liquid crystal array [8197-84]

X. Zhang, Nanjing Institute of Astronomical Optics \& Technology (China), Key Lab. of Astronomical Optics \& Technology (China), and Graduate Univ. of the Chinese Academy of Sciences (China); D. Ren, Nanjing Institute of Astronomical Optics \& Technology (China), Key Lab. of Astronomical Optics \& Technology (China), and California State Univ., Northridge (United States); Y. Zhu, J. Dou, Nanjing Institute of Astronomical Optics \& Technology (China) and Key Lab. of Astronomical Optics \& Technology (China); X. Wang, Nanjing Institute of Astronomical Optics \& Technology (China), Key Lab. of Astronomical Optics \& Technology (China), and Graduate Univ. of the Chinese Academy of Sciences (China)

\section{SESSION 6 OPTICAL SYSTEMS AND LASERS}

8197 ON The character of branch points' variation in laser propagation through atmosphere [8197-57]

X. Ge, Shandong Univ. of Technology (China); C. Fan, X. Feng, Anhui Institute of Optics and Fine Mechanics (China); C. Li, X. Liu, S. Fu, Shandong Univ. of Technology (China)

819700 Numerical analysis of fundamental mode selection of a He-Ne laser by a circular aperture [8197-07]

X. He, B. Zhang, National Univ. of Defense Technology (China)

POSTER SESSION

8197 OP Design and simulation of optical system based on microlens array for scannerless pulsed laser radar [8197-03]

X. Cai, X. Leng, J. Liu, Heilongjiang Univ. (China); Q. Han, Harbin Institute of Technology (China); W. Dai, Heilongjiang Univ. (China)

$81970 Q$ The application of diagnostic equipment in the Tokamak fusion reaction [8197-05] B. Zhang, J. Chang, Beijing Institute of Technology (China); X. Gong, J. Gan, Institute of Plasma Physics (China); S. Feng, Changchun Institute of Optics, Fine Mechanics and Physics (China)

8197 OR Linewidth narrowing and wavelength stabilization of high-power laser diode array by use of volume Bragg grating [8197-06]

H. Wang, X. Yuan, Soochow Univ. (China)

8197 OS Design of apochromatic telescopic optical system based on PWC method [8197-08] X.-X. Wei, F. XU, J. YU, Soochow Univ. (China)

8197 OT Writing on wet paper based on multipixel differencing [8197-14] X. Yang, L. Cao, Z. Chen, F. Li, B. Li, Z. WU, Tianjin Univ. of Technology (China)

8197 OU Design of airborne imaging spectrometer based on curved prism [8197-15] Y. Nie, The Academy of Opto-Electronics (China) and Graduate Univ. of the Chinese Academy of Sciences (China); B. Xiangli, J. Zhou, The Academy of Opto-Electronics (China); $X$. Wei, Soochow Univ. (China) 
8197 OV Impact of the light source expanded width on optical readout uncooled infrared system [8197-18]

Q. Jia, Y. Zhao, X. Liu, W. Zhu, G. Yin, L. Dong, Beijing Institute of Technology (China)

8197 OW PSF analysis on subaperture aberrations of optical synthetic aperture imaging system [8197-20]

Z. Wang, S. Zhang, Y. Jiang, L. Hao, L. Zhang, Harbin Institute of Technology (China)

8197 OX Research on the tangible tabletop interaction system based on the optical sensors [8197-21]

D. Feng, D. Weng, Y. Wang, Y. Liu, Beijing Institute of Technology (China)

8197 OY Optimization of laser induced breakdown spectroscopy system by neurogenetic method for multi-elemental analysis of heavy metals in soil [8197-23]

L. Liu, J. Liu, N. Zhao, Y. Wang, H. Shi, C. Wang, Y. Zhang, W. Liu, Anhui Institute of Optics and Fine Mechanics (China)

$81970 Z$ The model-based approach to wavefront sensorless adaptive optics in space remote imaging system [8197-27]

X. Ren, X. Zhang, Beijing Institute of Technology (China); B. Wang, China Academy of Space Technology (China); N. An, Heibei Univ. of Science and Technology (China)

819710 The study of transfer function characteristic of long-base laser strainmeters [8197-29] J. You, Harbin Engineering Univ. (China)

819711 Design study of optical fiber F-P sensing system for bio-tissue temperature real-time measurement [8197-33]

S. Ning, Engineering College of Armed Police Force (China); G. Heng, North China Univ. of Water Conservancy and Electric Power (China)

819712 Research of sampling interval in wavefront coded system [8197-35]

Z. Zhou, D. Wang, Y. Wang, Beijing Univ. of Technology (China)

819714 Precision measurement facility of mid-infrared spectral emissivity measurement [8197-38] G. Feng, Y. Wang, P. Li, National Institute of Metrology (China); T. Guo, Huaihai Institute of Technology (China); T. Guo, China Agricultural Univ. (China)

819715 Mid-wave infrared dual-field-of-view lenses with high ratio for third generation thermal imager [8197-40]

R. Li, X. Zhang, L. Liu, North China Research Institute of Electro-optics (China)

819716 Analysis of comprehensive influence of piston error and subapertures' aberrations upon sparse-optical-synthetic-aperture systems' image quality for the broadband target wave [8197-43]

Z. Liu, National Univ. of Defense Technology (China), Key Lab. on Adaptive Optics (China), and Institute of Optics and Electronics (China); S.-Q. Wang, L.-H. Huang, C.-H. Rao, Key Lab. on Adaptive Optics (China) and Institute of Optics and Electronics (China)

819717 Design of photoelectric autocollimator for NC rotary table position detection [8197-44]

M. Hu, B. Yan, L. Zhu, Beijing Information Science and Technology Univ. (China) 
819718 New system of miniaturization online testing of spherical interferometer [8197-48] J. Lin, Z. Han, J. Zhuo, M. Wang, Fujian Normal Univ. (China)

819719 The design of analysis system of refractive index profile of optical fiber [8197-54] G. He, Z. Liu, Harbin Engineering Univ. (China)

$81971 \mathrm{~A} \quad$ Flat-field EUV spectrometer and its performance test by Penning discharge source [8197-55] X. Du, Univ. of Science and Technology of China (China); Y. Shi, W. Zhang, Y. Shen, Institute of Plasma Physics (China); Q. Wang, Univ. of Science and Technology of China (China)

8197 1B Bandwidth determination of a Czerny-Turner double monochromator with varied slit widths through experiment and data computation [8197-56]

H. Ouyang, C. Dai, B. Huang, Z. Wu, National Institute of Metrology (China)

8197 1C An experimental apparatus for normal spectral emissivity measurement [8197-60] K. YU, Beijing Institute of Technology (China) and Xingyi Normal Univ. for Nationalities (China); Y. Liu, Beijing Institute of Technology (China) and Henan Normal Univ. (China); G. Jia, Beijing Institue of Technology (China); D. Shi, Henan Normal Univ. (China)

8197 1D Novel MOEMS-based beam steering method [8197-61]

J. Wang, Q. Hao, Y. Song, Y. Hu, Beijing Institute of Technology (China)

$81971 \mathrm{E}$ Research on the transmission of information on bi-grating diffraction imaging [8197-65] M. Huang, Quzhou Univ. (China); W. Zhang, Guangxi Univ. (China)

8197 IF A single channel input virtual dual-phase lock-in amplifier [8197-74]

Z. Gao, H. Zheng, L. Li, F. Chen, F. Guo, Fujian Normal Univ. (China)

$8197 \mathrm{1H} \quad$ Modeling of a field-widened Michelson interferometric filter for application in a high spectral resolution lidar [8197-80]

D. Liu, C. Hostetler, A. Cook, NASA Langley Research Ctr. (United States); I. Miller, LightMachinery Inc. (Canada); J. Hair, NASA Langley Research Ctr. (United States)

$819711 \quad$ A dual-channel imaging polarimetry system [8197-83]

$X$. Wang, Nanjing Institute of Astronomical Optics \& Technology (China), Key Lab. of Astronomical Optics \& Technology (China), and Graduate Univ. of the Chinese Academy of Sciences (China); D. Ren, Nanjing Institute of Astronomical Optics \& Technology (China), Key Lab. of Astronomical Optics \& Technology (China), and California State Univ., Northridge (United States); J. Dou, Y. Zhu, Nanjing Institute of Astronomical Optics \& Technology (China) and Key Lab. of Astronomical Optics \& Technology (China); X. Zhang, Nanjing Institute of Astronomical Optics \& Technology (China), Key Lab. of Astronomical Optics \& Technology (China), and Graduate Univ. of the Chinese Academy of Sciences (China)

$81971 \mathrm{~J} \quad 2000 \mathrm{~W}$ high beam quality diode laser for direct materials processing [8197-87] W. Qin, Y. Liu, Y. Cao, J. Gao, F. Pan, Z. Wang, Beijing Univ. of Technology (China)

$81971 \mathrm{~K} \quad$ Research of zernike fitting algorithm in finite element process [8197-90] X.-F. Song, L. Li, Y.-F. Huang, S.-Y. Lu, Beijing Institute of Technology (China) 
$8197 \mathrm{lL}$ The method of identification of cloud phase by using micropulse lidar [8197-94] L. Wang, H. Chen, Y. Zhang, S. Chen, P. Guo, Beijing Institute of Technology (China)

Author Index 


\section{Symposium Committee}

General Chairs

Songlin Zhuang, University of Shanghai for Science and Technology (China)

Brian Culshaw, University of Strathclyde (United Kingdom)

Conference Cochairs

Yuri Chugui, New Siberia Academy of Sciences (Russian Federation)

Arthur Chiou, National Yang-Ming University (Taiwan, China)

Shenghua Ye, Tianjin University (China)

Honorary Chairs

Daheng Wang, Chinese Academy of Sciences (China)

Guoguang Mu, Nankai University (China)

Bingkun Zhou, Tsinghua University (China)

Technical Program Chair

Guofan Jin, Tsinghua University (China)

Technical Program Cochairs

Jinxue Wang, SPIE

Yimo Zhang, Tianjin University (China)

Local Organizing Committee Chair

Youhua Wu, China Instrument and Control Society (China)

Local Organizing Committee Cochairs

Guoqiang Ni, Beijing Institute of Technology (China)

Daoyin Yu, Tianjin University (China)

Yulin Xi, Beijing Hamamatsu Photon Techiques Inc. (China)

General Secretary

Youhua Wu, China Instrument and Control Society (China) 
Administrative Vice General Secretary

Boyu Ding, Beijing Institute of Technology (China)

Vice General Secretaries

Yuejin Zhao, Beijing Institute of Technology (China)

Tiegen Liu, Tianjin University (China)

Qionghui Feng, University of Shanghai for Science and Technology (China)

Cunlin Zhang, Capital Normal University (China)

Local Organizing Committee

Duanyi Xu, Tsinghua University (China)

Weimin Chen, Chongqing University (China)

Hongda Chen, Institute of Semiconductors (China)

Shangzhong Jin, China Jiliang University (China)

Libo Yuan, Harbin Engineering University (China)

Chunqing Gao, Beijing Institute of Technology (China)

Shiqiao Qin, National University of Defense Technology (China)

Tian Lan, Beijing Institute of Technology (China)

Cuiling Li, Beijing Institute of Technology (China)

Liquan Dong, Beijing Institute of Technology (China) 


\title{
Conference Committee
}

\author{
Conference Chairs
}

Yongtian Wang, Beijing Institute of Technology (China)

Yunlong Sheng, Centre d'optique, photonique et laser, Université Laval (Canada)

Han-Ping Shieh, National Chiao Tung University (Taiwan, China)

Kimio Tatsuno, Hitachi, Ltd. (Japan)

Program Committee

Jiabi Chen, University of Shanghai for Science and Technology (China)

Chunlei Du, Institute of Optics and Electronics (China)

Jia-Ruey Duann, Industrial Technology Research Institute (Taiwan, China)

Sen Han, Veeco Instruments (United States)

Qun Hao, Beijing Institute of Technology (China)

Mei-Li Hsien, National Taiwan Normal University (Taiwan, China)

Hong Hua, College of Optical Sciences, The University of Arizona (United States)

Ken Y. Hsu, National Chiao Tung University (Taiwan, China)

Hisao Kikuta, Osaka Prefecture University (Japan)

Tsuyoshi Konishi, Osaka University (Japan)

Irina Livshits, St. Petersburg State University of Information Technologies, Mechanics and Optics (Russian Federation)

Xiang Peng, Shenzhen University (China)

Jannick Rolland, University of Rochester (United States)

Xiaodi Tan, Sony Corporation (Japan)

Yeong-Shin Tarng, National Taiwan University of Science and Technology (Taiwan, China)

Din Ping Tsai, National Taiwan University (Taiwan, China)

Willi Ulrich, Carl Zeiss (Germany)

H. Paul Urbach, Delft University of Technology (Netherlands)

Yuejin Zhao, Beijing Institute of Technology (China)

Session Chairs

1 Optical Measurement

Yunlong Sheng, Centre d'optique, photonique et laser, Université Laval (Canada)

2 Optical Sensing and Testing

Nandini Bhattacharya, Technische Universität Delft (Netherlands) 
3 Nano- and Micro-Optics

Hexin Wang, Carl Zeiss Jena GmbH (Germany)

$4 \quad$ Optical Elements and Systems

Kimio Tatsuno, Hitachi, Ltd. (Japan)

$5 \quad$ Optical Systems Design

Yongtian Wang, Beijing Institute of Technology (China)

$6 \quad$ Optical Systems and Lasers

Dongdong Weng, Beijing Institute of Technology (China) 


\section{Introduction}

These proceedings are from the 2011 International Conference on Optical Instrument and Technology (OIT2011), held in Beijing, China, 7-9 November 2011. The conference was the third event following the success of OIT'08 and OIT'09 and was sponsored and supported by SPIE, China Instrument and Control Society (CIS), and the Chinese Optical Society (COS).

OlT2011 was a professional conference which was combined and focused on instrument science and related technology, and involved in many technical aspects such as detection; observation; information collection, transfer and storage; communication; economization on energy; environmental protection; inspection and prevention of food security, traffic safety and mine safety; measure and control for aviation and space engineering, etc.

These proceedings, a collection of six volumes, contain the accepted oral and poster papers presented at OIT2011. It is truly a great pleasure for me that the most recent progress in optical instrumentation technology is reported in the OIT2011 proceedings. I firmly believe that the papers included in these volumes will provide reference information in the most up-to-date techniques of optical instrumentation technology.

The OIT2011 conference collected over 330 papers from different countries or regions of the world. Over 300 authors came from more than 12 countries. This conference consists of eight oral sessions (and a one-day poster session): Optical Systems and Modern Optoelectronic Instruments; Optical Device \& Integration; Optical Sensor and Applications; Opto-electronic Imaging and Processing Technology; Optoelectronic Measurement Technology and System; Solid State Lighting and Display Technologies; Holography, Speckle Pattern Interferometry and Application; Micro/Nano Manufacturing and Metrology. Published in these six volumes of the Proceedings of SPIE are close to 330 papers. The technical fields of the presented papers at the conference cover a lot of current advanced technologies. The cutting-edge technologies and applications of optical instruments are discussed. Quite a few invited papers describe exciting achievements in the fields of optical instrument technology. It is evident that the OlT2011 conference has provided an excellent platform for participants and colleagues in research and development to share the technical progress and to develop new partnerships or broaden new markets.

SPIE has given great support to organize this international conference by collaborating with us in the whole organizing process from abstract collection to the proceedings publication. COS has provided great support and assistance. 
Finally, on behalf of CIS and conference general chairs, I would like to heartily thank our supporters and committee members for all they have done for this conference. Thanks also go to all authors for their contributions, to all of the participants and friends for their interest, especially those who have traveled great distances and taken time from their busy schedules to attend the conference. Thanks also go to the staff of CIS for their support. I am also grateful to the SPIE staff for their support and collaboration in publishing these six volumes.

Songlin Zhuang

Chairman, China Instrument and Control Society (CIS) 